\title{
Stature Estimation from Body Segment Lengths in Young Adults -Application to People with Physical Disabilities-
}

\author{
Alicia Canda \\ Sports Medicine Centre, General Sub-directorate of Sport and Health, High Council for Sports, Spain
}

\begin{abstract}
Knowledge of stature is necessary for evaluating nutritional status and for correcting certain functional parameters. Measuring stature is difficult or impossible in bedridden or wheelchair-bound persons and may also be diminished by disorders of the spinal column or extremities. The purpose of this work is to develop estimation equations for young adult athletes for their subsequent application to disabled persons. The main sample comprised 445 male and 401 female sportspersons. Cross validation was also performed on 100 males and 101 females. All were Caucasian, the males being over 21 and the females over 18, and all practiced some kind of sport. The following variables were included: stature, sitting height, arm span, and lengths of upper arm, forearm, hand, thigh, lower leg, and foot. Simple and multiple regression analyses were performed using stature as a dependent variable and the others as predictive variables. The best equation for males $\left(R^{2}=0.978 ; \mathrm{RMSE}=1.41 \mathrm{~cm}\right.$; $\mathrm{PE}=1.54 \mathrm{~cm})$ was stature: $1.346+1.023 *$ lower leg $+0.957 *$ sitting height $+0.530 *$ thigh $+0.493 *$ upper $\operatorname{arm}+0.228 *$ forearm. For females $\left(R^{2}=0.959 ; \mathrm{RMSE}=1.57 \mathrm{~cm} ; \mathrm{PE}=1.25\right.$ $\mathrm{cm})$ it was stature: $1.772+0.159 *$ arm span $+0.957 *$ sitting height $+0.424 *$ thigh $+0.966 *$ lower leg. Alternative equations were developed for when a particular variable cannot be included for reasons of mobility, technical difficulty, or segment loss. J Physiol Anthropol 28(2): 71-82, 2009 http://www.jstage.jst.go.jp/browse/jpa2
\end{abstract}

[DOI: $10.2114 / j p a 2.28 .71]$

Keywords: stature, proportionality, regression equations, sportspersons

\section{Introduction}

Stature or standing height is defined as the distance between the head vertex and the standing surface. Its dimension depends on the length of various segments: cephalic, spinal, pelvic, and lower limbs. It is considered to be one of the most important indicators of body size.

Adult human stature is the result of a multifactorial biological process. Determining factors (polygenic inheritance) define the physiological potential while environmental conditions (nutrition, climate, oxygen, affectivity) and the degree of environmental adaptability will determine to what extent this potential is realized. Growth follows a specific pattern which is genetically controlled, in which body segments grow at different rates following a cranio-caudal sequence. As a result the proportion between body segments changes. Consequently the influence that the various factors have on the length of body segments will vary depending on when they interact, providing a greater or lesser performance from a biomechanical viewpoint. The regulation of all the factors involved in this process is known as whole-body coordination (Kouda, 2005; Iwanaga, 2005). Changes recorded in stature (secular trend) of various populations at different times in their history are a true reflection of environmental conditions, stature being considered an index of welfare and socioeconomic progress (Fogel, 1994; Eveleth and Tanner, 1990). In Japan it has been confirmed that the increase in height in recent years is mainly due to an increase in the length of the lower limbs (Tanner et al., 1982; Ohyama et al., 1987).

It is sometimes difficult to measure stature accurately in debilitated people such as the elderly or the sick when it is impossible to put them in the right position. In other cases the problem is due to lower limb amputations caused by accident or disease. These people tend to be bedridden and/or move with the aid of a wheelchair, prosthesis, or crutches. Finally, stature may be diminished by disorders either in the spinal column (osteoporosis, kyphosis, or scoliosis) or in the lower limbs (contractures), and may also be due to the effect of aging. Since the determination of stature is necessary for medical assessment and nutritional control, regression equations have been developed to estimate it from other anthropometric variables that are easy to obtain and are closely related to stature (Harris and Benedict, 1918; Forbes, 1974; Knudson et al., 1976; Frisancho, 1984; Golshan et al., 2003; Engeland et al., 2003).

These techniques originate from forensic anthropology, responsible for the identification of human remains. One of two basic methods is used: either the anatomical method, based 
on the direct reconstruction of stature, or the mathematical method, based on the correlation between skeletal components with stature, either by applying a multiplication factor (height divided by bone length) or regression equations (Nath and Badkur, 2002). A forerunner of these techniques is the study of skeletal proportions, such as the work presented to the French Academy of Sciences by Sue in the 18th century (Villanueva and Castilla, 1998). However, the first tables for the estimation of stature, based on the length of the 6 long limb bones, date back to 1888 and the work of the Frenchman Rollet, subsequently modified by Manouvrier (1893) and Karl Pearson (1899) (in Trotter, 2004). The most important development in this field was made by Trotter and Gleser $(1958,1977)$, who estimated stature from the length of long limb bones as part of a study of the identification of World War 2 and Korean War soldiers. Other works include those of Dupertuis and Hadden (1951), Genovés (1967), Telkka (1950), and more recently the work that Nunes de Mendoça (1998) carried out on a Portuguese population.

The first equations for estimating the height of living people for practical application were developed by Zorab, Prime, and Harrison in 1963. Their work was based on a sample of 177 children of European extraction of both sexes with a mean age of 12.8 years. The work arose from the need to evaluate pulmonary function in children and young people suffering from short stature due to spinal column disorders, for whom normal age, gender, and height references were not valid. Length of tibia was used as a predictive variable.

Since then the field of application of stature estimation has widened; it is no longer the sole province of archaeology and forensics but is also used for living persons. Accuracy in stature estimation depends to some extent on the specificity of the samples on which the estimation is based and can be influenced by such factors as age range, sex, ethnicity, and socioeconomic level. This explains why, over the years, a number of authors have developed equations to be applied to various specific subpopulations (Saxena, 1984; Bhatnagar, et al., 1984; Hibbert et al., 1988; Steele and Chenier, 1990; Giles and Vallandigham, 1991; Gordon and Buikstra, 1992; Singh and Phookan, 1993; Jarzem and Gledhill, 1993; Brown et al., 2000).

Perhaps the most important work was done by Chumlea, et al. (1985), who used the measurement of knee height to estimate the stature of men and women from 60 to 90 years old. Later, Chumlea et al. (1994) developed equations that were applicable to the adult and infant population, using a sample from National Health Examination Surveys (NHES) I, II, and III conducted between 1960 and 1970. More recently still, in 1998, they widened their study and developed equations for the elderly US population (over 60 years old).

One of the areas in which stature estimation equations may be applied is for persons with a physical disability whose stature cannot be measured by conventional methods due to disorders of the spinal column or the extremities or because their stature may be underestimated due to those disorders.
Since Ludwig Guttman (1944, England) introduced competitive sport as an essential part of the medical rehabilitation of his patients with spinal cord lesions, many disabled people have engaged in physical activities, ranging from purely recreational activities to top-level competition.

The hypothesis under study is that new predictive equations with better correlation coefficients using more anthropometric variables can be developed for use with young adult Caucasians, and that the predictive capability of the equations can be increased by this association of variables. Since it is sometimes impossible to measure a given variable, either due to a lack of any reliable measuring device or due to the nature of the disability itself, we believe it is important to provide alternative equations with different variables so as to be able to choose the best one for each particular case. Thus the objective of this paper is to develop stature estimation equations based on body segment lengths of young adult sportspersons, to be applied in the field of functional assessment for persons with physical disability.

\section{Methods}

\section{Subjects}

The study was conducted on a sample comprising a total of 1047 sportspersons, 545 male and 502 female. All these sportspersons competed at a national and/or international level. The mean age of the male sample was $25.7 \pm 3.9$ years and that of the female sample was $23.1 \pm 4.8$ years. The training profile of the group under study was: $11 \pm 4.8$ years of training, $5.7 \pm 1.1$ days a week, and $3.5 \pm 1.2$ hours a day for the males; and $9.5 \pm 4.6$ years of training, $5.5 \pm 1.1$ days a week, and $3.3 \pm 1.4$ hours a day for the females.

The sample were all Spanish sportspersons who had been to a sports medical check-up at the Medical Center of the High Council for Sports between the years 1999 and 2006. The age range for males was from 21 to 40 years old, and for females from 18 to 40. All were Caucasian and any person suffering from syndromes associated with disorders in stature and/or body proportions was excluded.

The sample was divided into two groups: a first group to obtain the regression equations and for simple validation, and a smaller group for cross-validation. The two groups were formed by random selection from among the various sports.

The first group comprised 846 sportspersons: 445 males and 401 females. In the male sample the following sports were represented: athletics $(n=157)$, badminton $(n=5)$, basketball $(n=35)$, boxing $(n=25)$, canoeing and kayaking $(n=19)$, fencing $(n=13)$, gymnastics (8), golf $(n=3)$, field hockey $(n=15)$, indoor football $(n=20)$, judo $(n=58)$, karate $(n=9)$, kickboxing $(\mathrm{n}=17)$, lifesaving $(\mathrm{n}=1)$, Olympic shooting $(n=25)$, swimming $(n=13)$, taekwondo $(n=3)$, tennis $(n=1)$, and wrestling $(n=18)$. The female sample comprised: artistic skiing $(n=2)$, athletics $(n=91)$, badminton $(n=6)$, basketball $(\mathrm{n}=16)$, baseball $(\mathrm{n}=1)$, boxing $(\mathrm{n}=2)$, cross-country skiing $(\mathrm{n}=5)$, cycling $(\mathrm{n}=2)$, fencing $(\mathrm{n}=11)$, field hockey $(\mathrm{n}=50)$, 
golf $(n=2)$, gymnastics $(n=19)$, judo $(n=69)$, karate $(n=7)$, kayaking $(n=20)$, kickboxing $(n=1)$, mountaineering $(n=1)$, Olympic shooting $(n=28)$, orienteering $(n=1)$, rowing $(n=7)$, skating $(n=1)$, soccer $(n=1)$, softball $(n=3)$, squash $(n=2)$, swimming $(\mathrm{n}=34)$, taekwondo $(\mathrm{n}=8)$, tennis $(\mathrm{n}=1)$, and wrestling $(n=10)$.

201 sportspersons, 100 males and 101 females, took part in the cross-validation study. The male sample comprised: alpine skiing $(n=1)$, archery $(n=4)$, handball $(n=1)$, cross-country skiing $(n=3)$, cycling $(n=16)$, motorcycling $(n=1)$, orienteering $(n=5)$, paddleball (19), rugby $(12)$, sailing $(n=3)$, triathlon $(n=33)$, and weight lifting $(n=2)$. In the female sample the following sports were represented: alpine skiing $(n=11)$, archery $(n=7)$, handball $(n=18)$, paddleball $(n=19)$, triathlon (30), and weight lifting $(n=16)$.

All the sportspersons signed an informed consent form authorizing the use of their data for research purposes provided confidentiality be maintained.

\section{Measurements}

The anthropometric techniques employed were standardized by the International Society for the Advancement of Kinanthropometry (ISAK) and the author of the work was ISAK-certified at Level 3 or Instructor level. The protocol was performed first thing in the morning to avoid diurnal variation in stature.

The anthropometric variables used in the stature estimation were: stature, sitting height, arm span, upper arm length, forearm length, hand length, thigh length, lower leg length, and foot length. Body weight was also included to complete the anthropometric study.

The anthropometric equipment consisted of the following items: scales, for measuring body weight (Seca Delta digital model, weighing capacity from $0.1 \mathrm{~kg}$ to $360 \mathrm{~kg}$ ); a stadiometer, for measuring stature (from Holtain Limited, with a measuring range of $700 \mathrm{~mm}$ to $2,200 \mathrm{~mm}$, accurate to $1 \mathrm{~mm}$ ); a sitting height table (from Holtain Limited, with a measuring range of $300 \mathrm{~mm}$ to $1105 \mathrm{~mm}$, accurate to $1 \mathrm{~mm}$ ); an anthropometer in canvas bag (from GPM Siber Hegner Machinery Limited, length of scale $0-2100 \mathrm{~mm}$, accurate to $1 \mathrm{~mm}$ ), and a measuring board, for measuring arm span (made by the anthropometry department using millimeter graph paper).

\section{Data analysis}

All the values obtained were analyzed by descriptive statistics. Sexual dimorphism analysis was performed using the Student's t-distribution for unpaired data, and significant difference was considered to be $p \leq 0.05$.

The relationship between variables was expressed using Pearson's correlation coefficient $(r)$ and, after checking for statistical significance $(p \leq 0.05)$, the corresponding regression equations were determined and validated by simple and cross validation. Stature was considered as the dependent response variable (y) and the other lengths as the predictive or independent variables (x). Firstly a simple regression was performed, then a multiple regression was run associating two or more predictive variables. The stepwise regression method was used, in which each variable is evaluated according to its contribution to the $R^{2}$ and is only included if it is statistically significant. Three different cases were considered to decide which variables to include. In the first case, where the subject was only incapable of standing, all the predictive variables were included. In the second case, where the subject was unable to keep the trunk erect, sitting height was excluded and the remaining variables were included. In the third case, involving amputations or segment loss in addition to one of the above circumstances, the relevant variables were excluded from the study according to the type of disability.

To assess the accuracy of the estimation equations a simple validation was performed using the root mean square error (RMSE), while cross validation was used to assess the accuracy of the estimation equations for the second group of sportspersons in order to calculate the pure error (PE).

Student's t-distribution was used for paired data to compare the height estimated by our equation and by equations from other authors. The technical error of measurement (intraobserver TEM) was determined for 20 of the subjects and was found to be within the range established by the ISAK.

\section{Results}

\section{Anthropometrics characteristics}

First, all the data from the anthropometric variables of the sample were analyzed, i.e., for the 1047 sportspersons (545 males and 502 females). The general anthropometric characteristics are shown in Table 1, where we can see the mean, the standard deviation, and the range.

The distribution of stature values (stature being the anthropometric measurement which we use as our dependent variable in the regression analysis) for both male and female samples is shown in Fig. 1. In males, stature varied between a minimum of $150.4 \mathrm{~cm}$ and a maximum of $208.1 \mathrm{~cm}$ (mean: $179.4 \mathrm{~cm})$. In females, stature values varied between a minimum of $147.4 \mathrm{~cm}$ and a maximum of $196 \mathrm{~cm}$. (mean: $166.5 \mathrm{~cm})$.

Table 2 shows the same statistics for the various body segment variables: length of upper arm, forearm, hand, thigh, lower leg, and foot.

All the anthropometric dimensions measured directly showed statistically significant differences between males and females, with a $p<0.0001$ for both sexes, with females having a lower mean value for all the above-mentioned parameters than males.

\section{Simple linear regression}

First we constructed a correlation matrix (Table 3) to see how closely the above-mentioned variables were interrelated, using the Pearson correlation coefficient $(r)$. Then we performed a simple linear regression analysis on each of the 
Table 1 General anthropometric characteristics of total sample

\begin{tabular}{|c|c|c|c|c|c|c|}
\hline & Age & Weight & Stature & Arm span & $\begin{array}{l}\text { Sitting } \\
\text { height }\end{array}$ & $\begin{array}{l}\text { Length of } \\
\text { lower limb }\end{array}$ \\
\hline \multicolumn{7}{|c|}{ Males $(n=545)$} \\
\hline Mean & 25.7 & 76.1 & 179.4 & 183.2 & 94.4 & 85.0 \\
\hline $\mathrm{SD}$ & 3.9 & 15.1 & 9.1 & 10.0 & 4.1 & 5.7 \\
\hline Range & 22.3 & 165.1 & 57.7 & 64.8 & 24.8 & 38.3 \\
\hline \multicolumn{7}{|c|}{ Females $(n=502)$} \\
\hline Mean & 23.1 & 60.8 & 166.5 & 167.7 & 88.2 & 78.3 \\
\hline $\mathrm{SD}$ & 4.8 & 11.2 & 7.6 & 8.7 & 3.5 & 4.8 \\
\hline Range & 23.6 & 91.2 & 48.6 & 56.3 & 23.2 & 31.6 \\
\hline
\end{tabular}

Age (years), Weight $(\mathrm{kg})$. Other variables' values in $\mathrm{cm}$

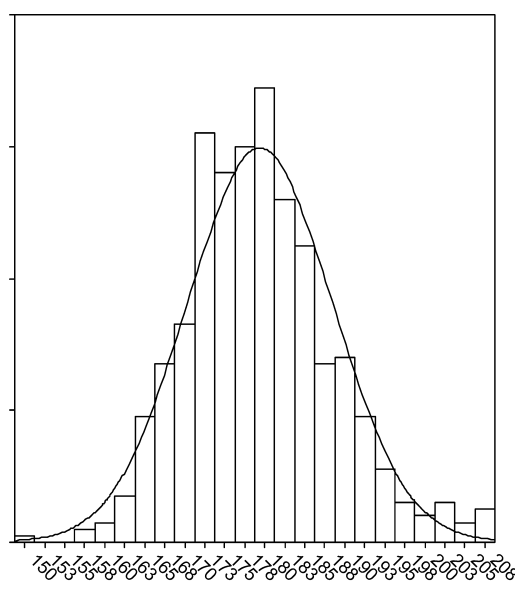

Males

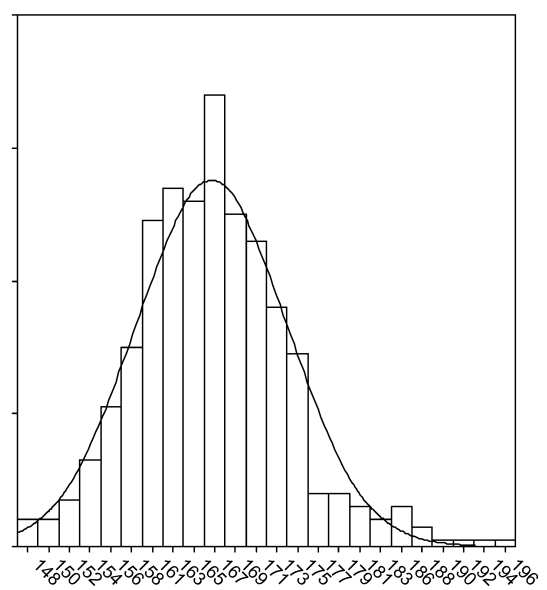

Females

Fig. 1 Distribution of stature $(\mathrm{cm})$.

Table 2 Body segment lengths of subjects $(\mathrm{cm})$

\begin{tabular}{|c|c|c|c|c|c|c|}
\hline & Upper arm & Forearm & Hand & Thigh & Lower leg & Foot \\
\hline \multicolumn{7}{|c|}{ Males $(n=545)$} \\
\hline Mean & 33.9 & 26.2 & 19.6 & 45.6 & 39.8 & 26.7 \\
\hline $\mathrm{SD}$ & 2.1 & 1.7 & 1.1 & 3.1 & 2.9 & 1.6 \\
\hline Range & 14.2 & 10.5 & 6.4 & 19.8 & 18.5 & 9.9 \\
\hline \multicolumn{7}{|c|}{ Females $(n=502)$} \\
\hline Mean & 31.3 & 23.7 & 17.9 & 42.8 & 36.8 & 24.1 \\
\hline $\mathrm{SD}$ & 1.9 & 1.5 & .9 & 2.8 & 2.5 & 1.3 \\
\hline Range & 11.9 & 9.2 & 5.5 & 17.6 & 16.2 & 8.5 \\
\hline
\end{tabular}

independent variables $(\mathrm{X})$, and the dependent variable, stature (Y). As goodness-of-fit parameters for our model we use the coefficient of determination $R^{2}$ and root mean square error RMSE (Simple Validation), and pure error PE (Cross Validation).

The results are displayed in Figs. 2 and 3, showing the regression straight lines $(p<0.0001)$. The equations are expressed as follows, $\mathrm{S} \mathrm{n}_{\mathrm{m} / \mathrm{f}}^{\circ}$ : $\mathrm{S}$ (simple regression), $\mathrm{n}^{\circ}$ (order number), $\mathrm{m}$ (male) or $\mathrm{f}$ (female) according to sex.

\section{Multiple linear regression}

For the first case we start by performing a multiple linear regression on stature with arm span, sitting height, and direct lower limb lengths. Foot length was not included as it does not increase reliability. In all the steps, $p$ was statistically significant with a value $<0.0001$. The process was then repeated but this time the arm span variable was replaced by direct upper limb lengths: upper arm, forearm, and hand lengths, with a $p<0.0001$. In this model, hand and foot lengths (in males) and forearm and hand lengths (in females) were not 
Table 3 Correlation Matrix: Pearson correlation coefficient

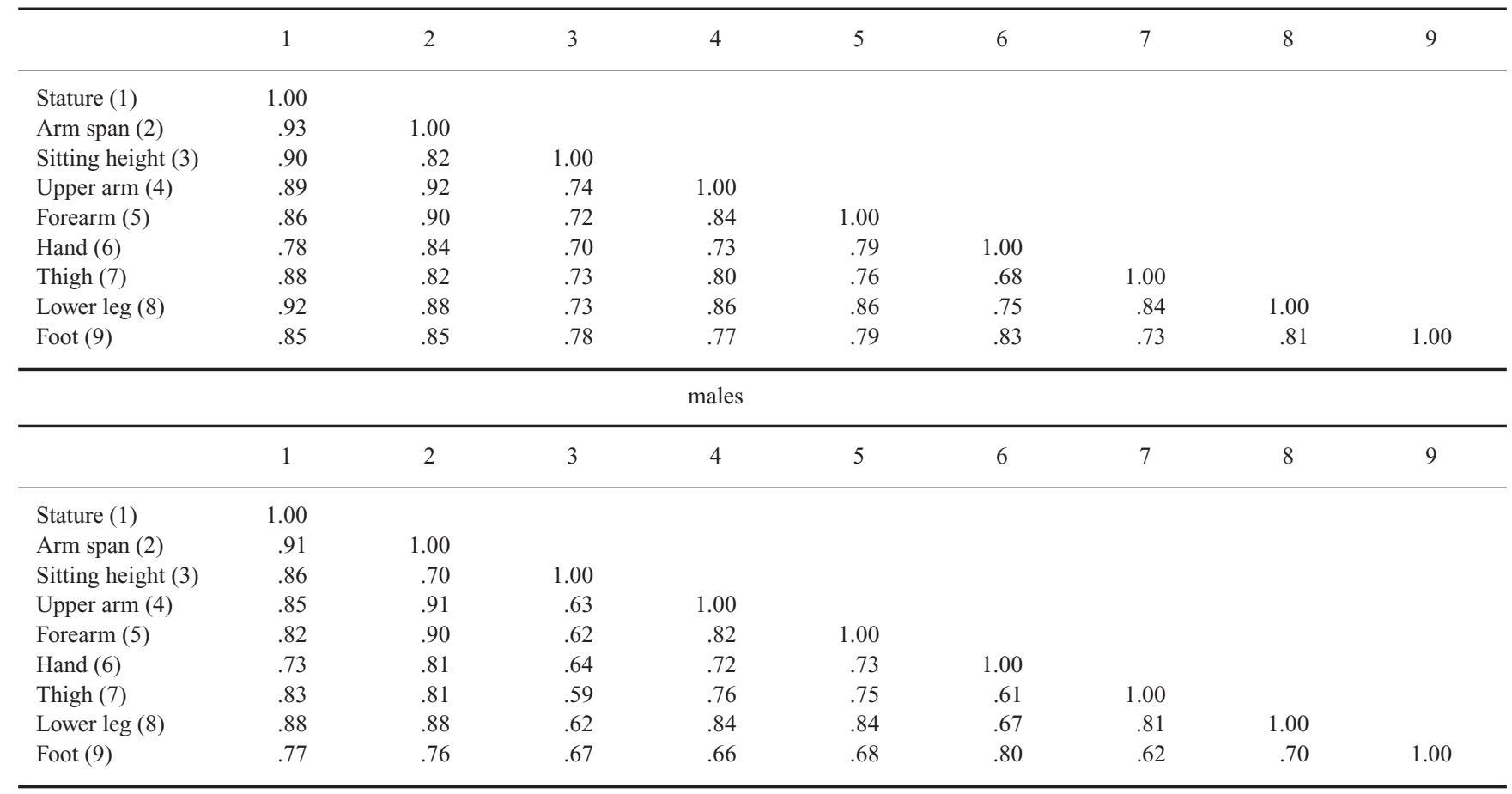

females

included as they do not increase statistical significance.

For the second case, when sitting height could not be measured properly due to the subject not being able to sit up straight or move from a lying position, we performed a regression model that excluded that variable, using direct lower limb lengths and arm span, or instead of the latter, direct upper limb lengths.

Finally, for the third case, involving amputations or loss of a limb or body segment, with or without the possibility of measuring sitting height properly, we performed multiple regression analysis by using the predictive variables corresponding to each particular case.

Tables 4 and 5 show the equations developed for the various cases, ranked from greater to lesser accuracy and precision.

\section{Discussion}

The sample used is large and representative. It includes a great many different sports, and each anthropometric measurement has a wide range of variation. The chosen age range (over 18 in females and over 21 in males, and under 40 in both sexes) provides a group with anthropometric variables that are fully developed but not yet affected by aging. We consider this to be fundamental for estimating stature, as it would not be right to correlate lengths in samples that included either subjects still growing and developing, or adults of advanced age. The study is also contemporaneous, taking in anthropometric research carried out between 1999 and 2006. There is a secular trend in the evolution of a number of anthropometric variables that makes it necessary to revise certain references obtained in the past, which may have altered over time. When comparing the mean height we obtained with the Spanish reference of Hernández et al. (1988) for 18-yearold males and females, we can see that the males, with a mean height of $179.4 \mathrm{~cm}$, exceed the reference height of $175.6 \mathrm{~cm}$ by $3.8 \mathrm{~cm}$. Meanwhile in our study the females had a mean height of $166.5 \mathrm{~cm}, 5.24 \mathrm{~cm}$ taller than the general female population $(161.26 \mathrm{~cm})$. In other words, sportspersons are taller than sedentary people although, as we mentioned, the fact that the reference values were obtained ten years before our study may have a bearing on this difference.

\section{Stature estimation equations}

Stature estimation is based on the relationship between height and certain anthropometric variables. In ancient times artists sought an ideal "canon of proportions" governing the proportions of the human body. They calculated height from the length of the head, estimating it to be the length of between 6 and 10 heads. However, the length of the head is not a variable used by scientists, who consider only postcranial measurements to be stature related.

With regard to forensic studies, the measurements that provide the best correlation are those based on the length of the long bones, followed by length of the spinal column. The first measurements correspond in external or surface anthropometry to the length of the segments of the extremities, and the second to the sitting height. Of the extremity bones, the lower limb bones give the best correlation. The results vary 

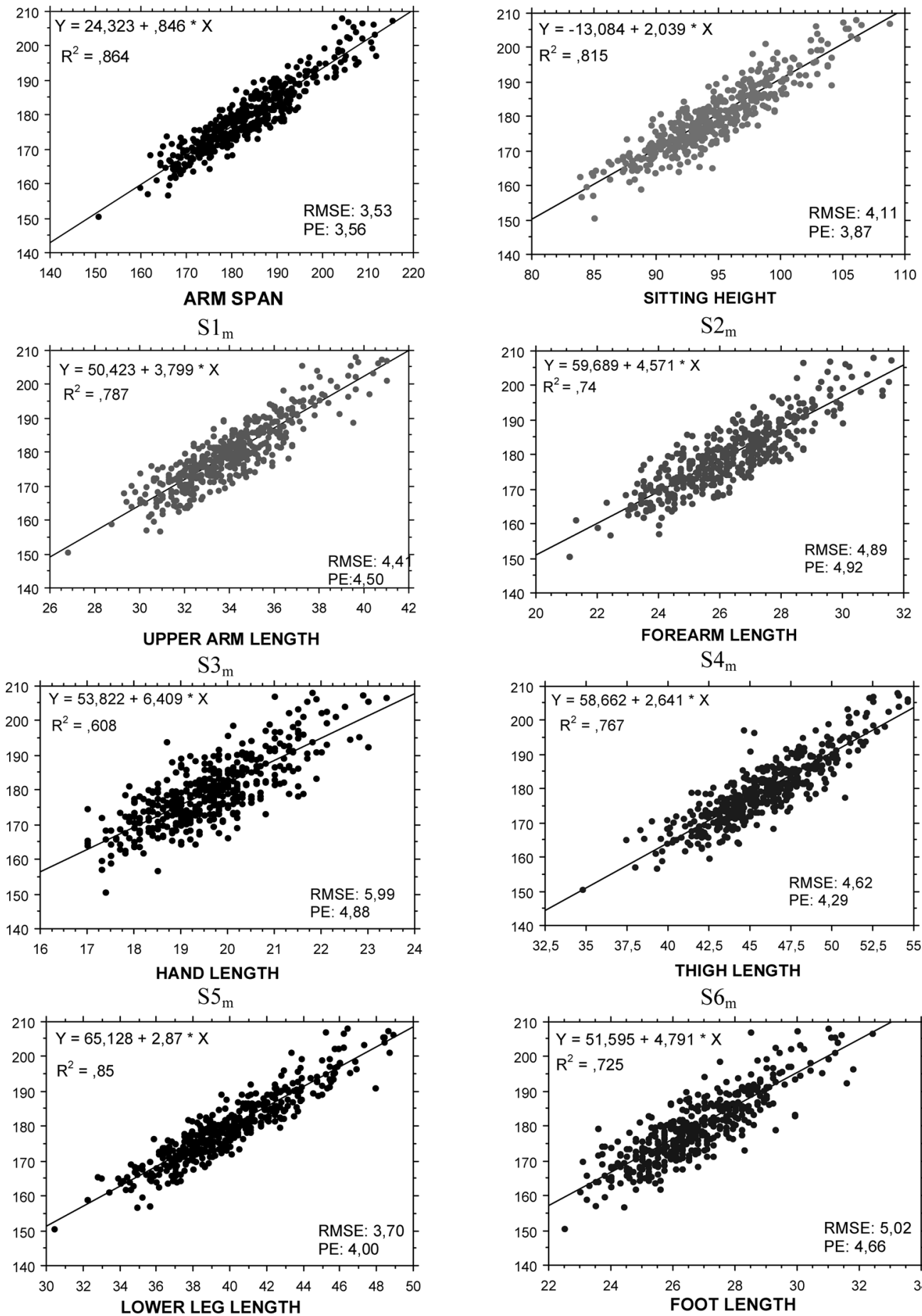

$\mathrm{S} 7_{\mathrm{m}}$

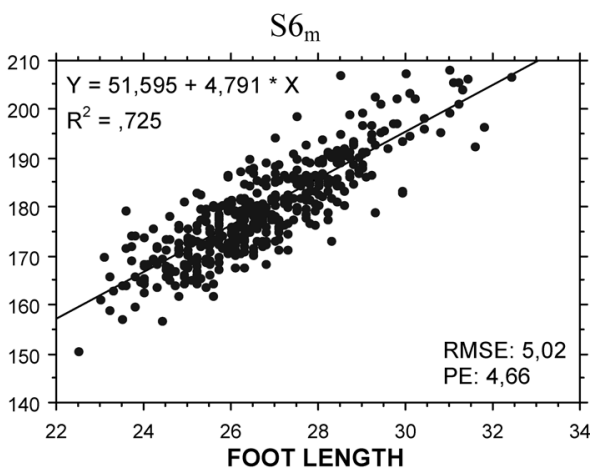

$\mathrm{S} 8_{\mathrm{m}}$

Fig. 2 Code $\mathrm{S} \mathrm{n}_{\mathrm{m}}^{\circ}$ : $\mathrm{S}$, simple regression equation; $\mathrm{n}^{\circ}$, serial number; $\mathrm{m}$ : male. RMSE: root mean square error. PE: pure error.

according to racial group and sex: for Caucasian males it is the femur followed by the fibula that give the smallest estimation error, while in Caucasian females the order is first the fibula, second the tibia, and then the femur. With regard to upper limb bones, in both sexes the humerus gives the best correlation (Trotter and Gleser, 1958, 1977). Of present day equations for
Caucasians perhaps the most interesting are those of Nunes de Mendoza in 1998, applied to a Portuguese sample (100 males and 100 females) aged between 20 and 59 years, estimating stature using femur and humerus length. The mean reference height is lower than our Spanish sample; $168 \mathrm{~cm}$ and $156 \mathrm{~cm}$, for males and females respectively. The coefficient of 


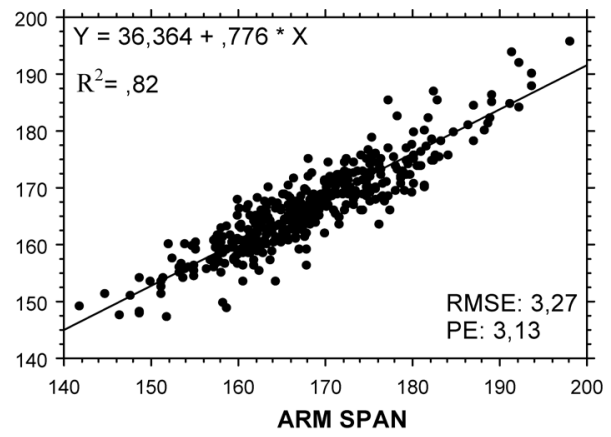

S1f

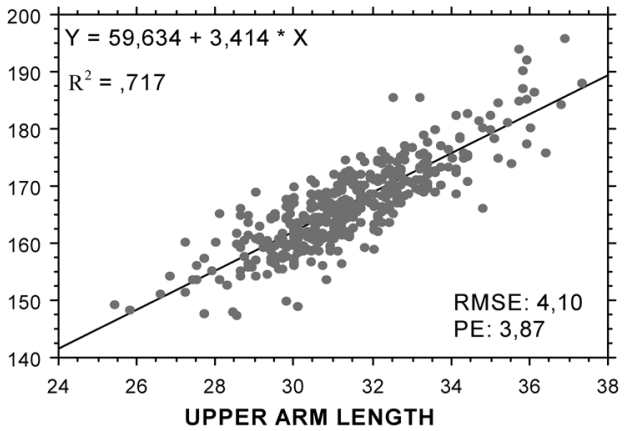

S3f

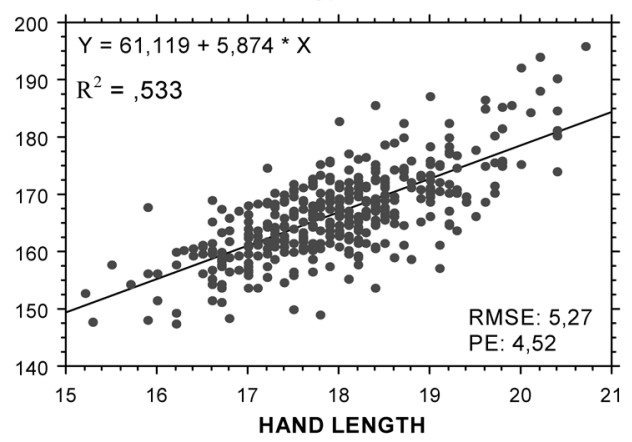

S5f

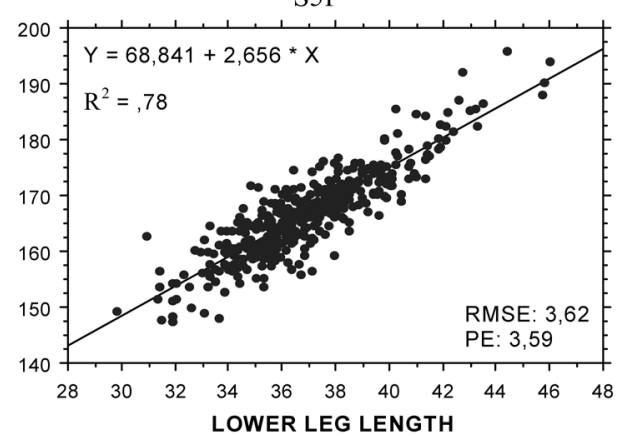

$S 7 f$

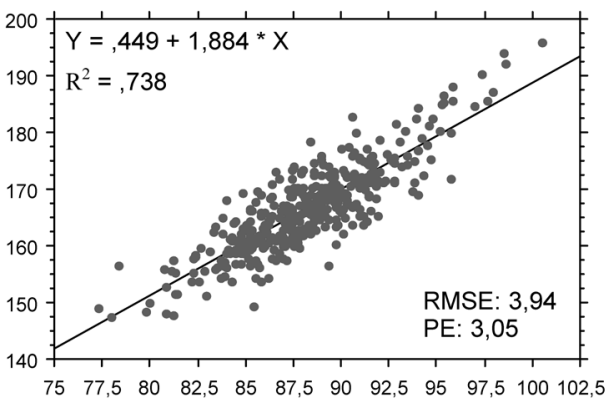

SITTING HEIGHT

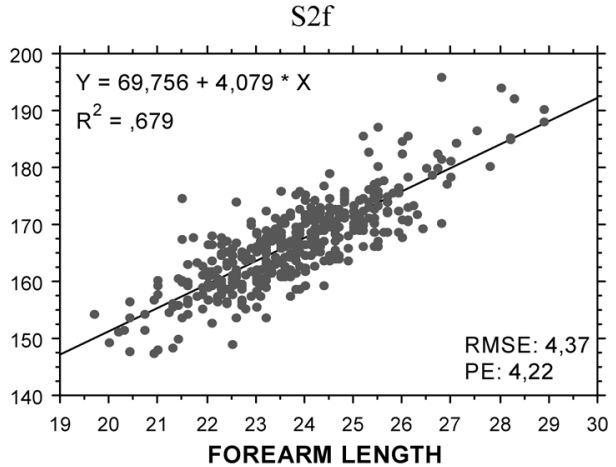

S4f

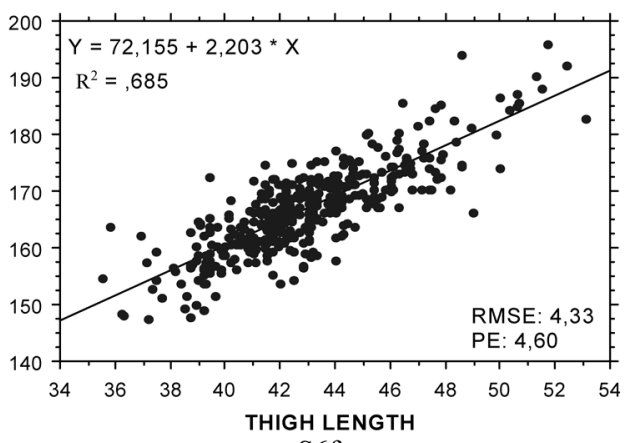

S6f

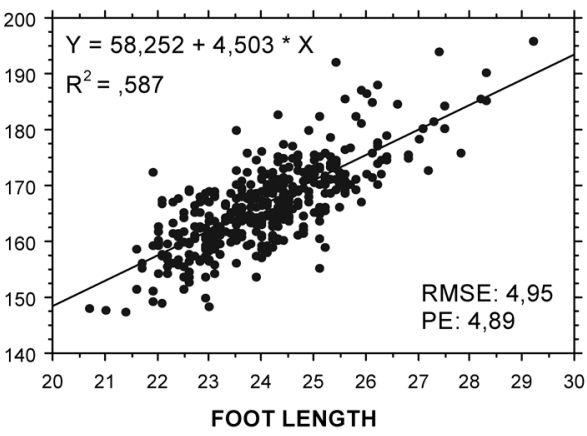

S8f

Fig. 3. Code $\mathrm{S} \mathrm{n}_{\mathrm{f}}^{\circ}$ : $\mathrm{S}$, simple regression equation; $\mathrm{n}^{\circ}$, serial number; $\mathrm{f}$ : female. RMSE: root mean square error. $P E$ : pure error.

determination $\left(R^{2}\right)$ for the femur (at physiological length) was 0.74 and 0.77 , for males and females respectively. The equivalent in our work would be thigh length, where in males we obtained a similar value $(0.77)$, while for females it is lower (0.68). In the case of the humerus, values of 0.61 and 0.60 for males and females respectively are lower than our equivalent coefficients for upper arm length (0.79 and 0.72).

In our height correlation matrix (Table 3), ranked in order from highest to lowest correlation, we find: arm span, lower leg length, sitting height, upper arm length, thigh length, forearm length, foot length, and length of the hand. In all variables females gave lower correlation values. It should be noted that 
Table 4 Regression equations on male sample

\begin{tabular}{|c|c|c|c|c|}
\hline Code & $R^{2}$ & RMSE & $\mathrm{PE}$ & Stature $(\mathrm{cm})=$ \\
\hline $\mathrm{M} 1_{\mathrm{m}}$ & 0.978 & 1.41 & 1.54 & $1.346+1.023 *$ lower leg $+0.957 *$ sitting height $+0.530 *$ thigh $+0.493 *$ upper arm $+0.228 *$ forearm \\
\hline $\mathrm{M} 2 \mathrm{~m}$ & 0.978 & 1.43 & 1.54 & $1.575+1.087 *$ lower leg $+0.969 *$ sitting height $+0.532 *$ thigh $+0.551 *$ upper arm \\
\hline $\mathrm{M} 3 \mathrm{~m}$ & 0.978 & 1.44 & 1.47 & $0.947+0.135 *$ arm span $+0.914 *$ sitting height $+0.545 *$ thigh $+1.067 *$ lower leg \\
\hline $\mathrm{M} 4_{\mathrm{m}}$ & 0.975 & 1.53 & 1.50 & $2.630+0.992 *$ sitting height $+1.245 *$ lower leg $+0.609 *$ thigh $+0.216 *$ foot \\
\hline $\mathrm{M} 5_{\mathrm{m}}$ & 0.974 & 1.54 & 1.49 & $2.590+1.027 *$ sitting height $+1.302 *$ lower leg $+0.613 *$ thigh \\
\hline $\mathrm{M} 6_{\mathrm{m}}$ & 0.969 & 1.69 & 1.77 & $2.354+0.179 *$ arm span $+0.948 *$ sitting height $+1.376 *$ lower leg \\
\hline $\mathrm{M} 7 \mathrm{~m}$ & 0.963 & 1.84 & 1.85 & $4.866+1.753 *$ lower leg $+1.109 *$ sitting height \\
\hline $\mathrm{M} 8_{\mathrm{m}}$ & 0.961 & 1.89 & 1.91 & $-5.272+0.998 *$ sitting height $+0.855 *$ thigh $+0.882 *$ upper arm $+0.820 *$ forearm \\
\hline $\mathrm{M} 9 \mathrm{~m}$ & 0.955 & 2.03 & 2.03 & $-6.059+1.059 *$ sitting height $+0.953 *$ thigh $+1.233 *$ upper arm \\
\hline $\mathrm{M} 10_{\mathrm{m}}$ & 0.936 & 2.43 & 2.62 & $-5.857+1.116 *$ sitting height $+1.435 *$ upper arm $+1.189 *$ forearm \\
\hline $\mathrm{M} 11_{\mathrm{m}}$ & 0.931 & 2.52 & 2 & $-7.517+1.283 *$ sitting height $+1.439 *$ thigh \\
\hline $\mathrm{M} 12_{\mathrm{m}}$ & 0.928 & 2.57 & 2.82 & $29.795+0.333 *$ arm span $+0.935 *$ lower leg $+0.673 *$ thigh $+0.771 *$ foot \\
\hline $\mathrm{M} 13_{\mathrm{m}}$ & 0.927 & 2.60 & 2.49 & $-9,049+0.527 *$ arm span $+0.973 *$ sitting height \\
\hline $\mathrm{M} 14_{\mathrm{m}}$ & 0.923 & 2.65 & 2.88 & $31.768+0.411 *$ arm span $+1.043 *$ lower leg $+0.673 *$ thigh \\
\hline M $15_{\mathrm{m}}$ & 0.922 & 2.67 & 2.97 & $-7.217+1.231 *$ sitting height $+2.075 *$ upper arm \\
\hline M $16_{\mathrm{m}}$ & 0.920 & 2.72 & 2.91 & $36.224+0.979 *$ lower leg $+0.856 *$ upper arm $+1.183 *$ foot $+0.723 *$ thigh $+0.402 *$ forearm \\
\hline $\mathrm{M} 17_{\mathrm{m}}$ & 0.918 & 2.73 & 2.85 & $37.010+1.075 *$ lower leg $+0.954 *$ upper arm $+1.270 *$ foot $+0.729 *$ thigh \\
\hline $\mathrm{M} 18_{\mathrm{m}}$ & 0.910 & 2.87 & 2.97 & $34.937+0.479 *$ arm span $+1.426 *$ lower leg \\
\hline M 19 m & 0.908 & 2.91 & 2.98 & $41.771+1.421 *$ lower leg $+1.518 *$ foot $+0.887 *$ thigh \\
\hline $\mathrm{M} 20_{\mathrm{m}}$ & 0.903 & 2.98 & 2.98 & $41.642+1.493 *$ lower leg $+1.238 *$ upper arm $+1.360 *$ foot \\
\hline $\mathrm{M} 21_{\mathrm{m}}$ & 0.890 & 3.19 & 3.38 & $31.176+1.382 *$ upper arm $+1.123 *$ thigh $+1.068 *$ forearm $+1.123 *$ hand \\
\hline $\mathrm{M} 22_{\mathrm{m}}$ & 0.884 & 3.25 & 3.18 & $50.870+1.899 *$ lower leg $+1.559 *$ upper arm \\
\hline $\mathrm{M} 23_{\mathrm{m}}$ & 0.883 & 3.23 & 3.61 & $37.026+1.507 *$ upper arm $+1.164 *$ thigh $+1.451 *$ forearm \\
\hline $\mathrm{M} 24_{\mathrm{m}}$ & 0.883 & 3.27 & 3.16 & $49.629+2.099 *$ lower leg $+1.732 *$ foot \\
\hline $\mathrm{M} 25_{\mathrm{m}}$ & 0.862 & 3.55 & 3.66 & $40.422+2.232 *$ upper arm $+1.382 *$ thigh \\
\hline $\mathrm{M} 26_{\mathrm{m}}$ & 0.844 & 3.79 & 3.88 & $35.854+2.203 *$ upper arm $+1.577 *$ forearm $+1.400 *$ hand \\
\hline M $27_{\mathrm{m}}$ & 0.834 & 3.91 & 4.15 & $43.424+2.398 *$ upper arm $+2.083 *$ forearm \\
\hline
\end{tabular}

Code $\mathrm{M} \mathrm{n}$ m $: M$, multiple regression equation; $\mathrm{n}^{\circ}$, serial number; $\mathrm{m}$ : male. RMSE: root mean square error. PE: pure error

Table 5 Regression equations on female sample

\begin{tabular}{|c|c|c|c|c|}
\hline Code & $R^{2}$ & RMSE & $\mathrm{PE}$ & Stature $(\mathrm{cm})=$ \\
\hline $\mathrm{M} 1_{\mathrm{f}}$ & 0.959 & 1.57 & 1.25 & $1.772+0.159 *$ arm span $+0.957 *$ sitting height $+0.424 *$ thigh $+0.966 *$ lower leg \\
\hline $\mathrm{M} 2_{\mathrm{f}}$ & 0.959 & 1.57 & 1.34 & $2.305+1.013 *$ lower leg $+0.970 *$ sitting height $+0.451 *$ thigh $+0.513 *$ upper arm $+0.253 *$ foot \\
\hline $\mathrm{M} 3_{\mathrm{f}}$ & 0.958 & 1.59 & 1.34 & $2.907+1.062 *$ lower leg $+1.005 *$ sitting height $+0.453 *$ thigh $+0.529 *$ upper arm \\
\hline $\mathrm{M} 4_{\mathrm{f}}$ & 0.955 & 1.65 & 1.33 & $3.326+1.007 *$ sitting height $+1.219 *$ lower leg $+0.523 *$ thigh $+0.299 *$ foot \\
\hline $\mathrm{M} 5_{\mathrm{f}}$ & 0.954 & 1.67 & 1.31 & $4.082+1.285 *$ lower leg $+1.049 *$ sitting height $+0.528 *$ thigh \\
\hline $\mathrm{M} 6_{\mathrm{f}}$ & 0.951 & 1.71 & 1.45 & $1.815+0.212 *$ arm span $+0.975 *$ sitting height $+1.173 *$ lower leg \\
\hline $\mathrm{M} 7_{\mathrm{f}}$ & 0.940 & 1.89 & 1.55 & $5.192+1.711 *$ lower leg $+1.116 *$ sitting height \\
\hline $\mathrm{M} 8_{\mathrm{f}}$ & 0.936 & 1.96 & 1.73 & $-0.126+1.022 *$ sitting height $+0.698 *$ thigh $+0.899 *$ upper arm $+0.779 *$ forearm \\
\hline $\mathrm{M} 9_{\mathrm{f}}$ & 0.929 & 2.06 & 1.92 & $-0.686+1.061 *$ sitting height $+0.814 *$ thigh $+1.237 *$ upper arm \\
\hline $\mathrm{M} 10_{\mathrm{f}}$ & 0.918 & 2.22 & 2.14 & $-4.102+0.509 *$ arm span $+0.966 *$ Sitting height \\
\hline $\mathrm{M} 11_{\mathrm{f}}$ & 0.911 & 2.3 & 2.04 & $-0.559+1.094 *$ sitting height $+1.325 *$ upper arm $+1.229 *$ forearm \\
\hline $\mathrm{M} 12_{\mathrm{f}}$ & 0.892 & 2.54 & 2.34 & $-1.663+1.184 *$ sitting height $+2.039 *$ upper arm \\
\hline $\mathrm{M} 13_{\mathrm{f}}$ & 0.894 & 2.51 & 2.23 & $0.685+1.246 *$ sitting height $+1.306 *$ thigh \\
\hline $\mathrm{M} 14_{\mathrm{f}}$ & 0.875 & 2.74 & 2.68 & $35.709+0.328 *$ arm span $+0.803 *$ lower leg $+0.535 *$ thigh $+0.973 *$ foot \\
\hline $\mathrm{M} 15_{\mathrm{f}}$ & 0.866 & 2.84 & 2.96 & $40.436+1.009 *$ lower leg $+1.359 *$ foot $+0.627 *$ thigh $+0.939 *$ upper arm \\
\hline M $16_{f}$ & 0.864 & 2.86 & 2.66 & $41.582+0.417 *$ arm span $+0.888 *$ lower leg $+0.522 *$ thigh \\
\hline $\mathrm{M} 17_{\mathrm{f}}$ & 0.852 & 2.98 & 2.77 & $42.556+0.489 *$ arm span $+1.142 *$ lower leg \\
\hline $\mathrm{M} 18_{\mathrm{f}}$ & 0.851 & 2.99 & 3.13 & $45.104+1.399 *$ lower leg $+1.526 *$ foot $+0.776 *$ thigh \\
\hline M $19_{\mathrm{f}}$ & 0.825 & 3.24 & 3.10 & $42.361+1.240 *$ upper arm $+0.934 *$ thigh $+1.239 *$ hand $+0.973 *$ forearm \\
\hline M $20_{f}$ & 0.822 & 3.26 & 3.36 & $50.489+2.047 *$ lower leg $+1.693 *$ foot \\
\hline $\mathrm{M} 21_{\mathrm{f}}$ & 0.815 & 3.33 & 3.20 & $41.502+1.578 *$ upper arm $+1.075 *$ thigh $+1.645 *$ hand. \\
\hline $\mathrm{M} 22_{\mathrm{f}}$ & 0.795 & 3.50 & 3.49 & $52.044+2.077 *$ upper arm $+1.154 *$ thigh \\
\hline $\mathrm{M} 23_{\mathrm{f}}$ & 0.780 & 3.63 & 3.36 & $46.344+1.870 *$ upper arm $+1.630 *$ forearm $+1.278 *$ hand \\
\hline $\mathrm{M} 24_{\mathrm{f}}$ & 0.769 & 3.71 & 3.57 & $53.970+2.105 *$ upper arm $+1.966 *$ forearm \\
\hline
\end{tabular}

Code $\mathrm{M} \mathrm{n}$ m $: M$, multiple regression equation; $\mathrm{n}^{\circ}$, serial number; $\mathrm{f}$, female. RMSE: root mean square error. PE: pure error 
thigh length (equivalent to femoral length), which in forensic medicine studies gives a better correlation than upper arm length (equivalent to humeral length), in our sample gives a worse correlation than upper arm length, especially in females. With regard to lengths of extremity segments, lower leg length has the greatest degree of correlation with the other lengths: 0.86 with upper arm and forearm lengths, and 0.84 with thigh length. Hand length correlates better with arm span and foot length than with stature, while foot length correlates equally well with height and arm span, and with hand length a little worse.

There is sexual dimorphism in the proportion of body segments, with females providing lower correlations than males. This difference may be due to both genetic load and the degree of adaptability to the environment.

\section{Estimation using simple regression}

Using simple linear regression we find that the isolated variable yielding the lowest error is arm span (equations $\mathrm{S1}_{\mathrm{m}}$ and $\mathrm{S1}_{\mathrm{f}}$ ), with a coefficient of determination $R^{2}$ of 0.864 in males and 0.820 in females. Another equation based on arm span is the one developed by Hibbert et al. (1988), not comparable with our study due to the different age range ( 8 to 18 years old). In 1990, Steele and Chenier developed another equation for females from the USA in which age was used as a predictive variable together with arm span. The model involved females from 35 to 89 years old, and had an $R^{2}$ of 0.903 . Their sample of 298 females with such a broad age range raises doubts as to whether the size of the sample is representative for each age range, as well as whether it is valid for people under 35 years of age. With regard to Jarzem and Gledhill's equation (1993), there are a number of points which lead us to the conclusion that it is unreliable, not the least of which is the size of the sample (only 61 males and 58 females, all Canadian) combined with a very broad age range (from 6 months to 56 years old), which means that the heights of children who are still growing and developing, each at their own particular stage of maturity, are being correlated with those of people who are already aging, making their coefficients of determination high but incorrect. Furthermore, neither age nor degree of maturity were accounted for in the regression equation, and measurements were made by tape measure, which may give rise to a greater degree of error in measurement. In Great Britain, Han and Lean's equation (1996), with a sample of 78 males and of 82 females aged between 17 and 70, yields a lower $R^{2}$ than our 0.64 for males and 0.68 for females, and a greater error, $4 \mathrm{~cm}$ and $3.7 \mathrm{~cm}$ respectively. The case of the equation developed by Brown, Whittemore and Knapp (2000) is similar: a small sample size (26 males and 57 females), a wide age range from 20 to 61 years old, and only $95 \%$ of the sample are said to be white. The rest of the equations based on arm span are not applied to Caucasian populations.

The second variable is lower leg length (equations: $\mathrm{S} 7_{\mathrm{m}}$ and $\mathrm{S}_{\mathrm{f}}$ ), with $R^{2}$ of 0.851 and 0.780 for males and females respectively. As we mentioned earlier, Zorab et al. (1963), who were the first to develop stature estimation equations for clinical application, used length of tibia, obtaining an estimation error of $3.93 \mathrm{~cm}$ and $3.87 \mathrm{~cm}$ for males and females respectively; in our work the error is slightly lower $(3.70 \mathrm{~cm}$ and $3.62 \mathrm{~cm}$ ). In addition to the equation involving arm span, Han and Lean (1996) developed another using lower leg length, but measured as the height to the upper margin of the patella. As we mentioned earlier, their sample ranged from 17 years old to 70. In Venezuela, Guzmán et al. (2005) measured with a tape measure the lower leg length of 90 males and 90 females aged between 30 and 59 years old, obtaining a lower $R^{2}$ in males than we obtained from our data, and a similar one in females. The method of measuring with a tape measure is less accurate than with an anthropometer or segmometer. Also, the measurement was taken from the external epicondyle of the femur to the sole of the foot, which was not the case in our sample. The other equations based on length of lower leg (tibia) by Ozaslan et al. (2003), and Duyar et al. (2006) refer to a population of Turkish origin, while the equation of Yousafzai et al. (2003) refers to an Indian population, and so neither are comparable.

Sitting height (equations $\mathrm{S} 2_{\mathrm{m}}$ and $\mathrm{S} 2_{\mathrm{f}}$ ) is the third variable which isolatedly has a higher coefficient of determination $\left(R^{2}\right.$ : 0.815 and 0.738 for males and females respectively) and a lower estimation error. However, in scientific literature there are no authors who propose using sitting height for estimating stature, since the correlation found in lower limb lengths are greater, and also it is unsuitable for use with bedridden subjects or those with disorders of the spinal column. Furthermore, soft tissue is involved; that is to say it is not a measurement of bones alone, which means that a greater or lesser development of the gluteal level will influence the measurement. In the case of persons with serious atrophy at this level, their stature will be underestimated while, conversely, if there is exceptional muscular development or an increase in the adipose panniculus, stature may be overestimated.

The next variables in descending order of coefficient are upper arm length (equations: $\mathrm{S} 3_{\mathrm{m}}$ and $\mathrm{S} 3_{\mathrm{f}}$ ) and thigh length (equations: $\mathrm{S}_{\mathrm{m}}$ and $\mathrm{S}_{\mathrm{f}}$ ). Upper arm length is included in the equation proposed by Jarzem and Gledhill (1993), which, as mentioned earlier, we do not consider appropriate. Other equations proposed refer to non-Caucasian populations and are therefore not comparable.

The sixth variable in descending order of correlation is forearm length (equations: $\mathrm{S} 4_{\mathrm{m}}$ and $\mathrm{S} 4_{\mathrm{f}}$ ), which would be equivalent to the length of the radius since it is measured from the part closest to the head of the radius to the lower edge of the styloid process. It is also one of the variables applied by Jarzem and Gledhill (1993), not independently but in conjunction with hand length.

The seventh variable is foot length (equations: $\mathrm{S} 8_{\mathrm{m}}$ and $\mathrm{S} 8_{\mathrm{f}}$ ). The broadest reference is the work of Giles and Vallandigham (1991), with an estimation error slightly lower than our 4.856 vs. 5.02 in males, and 4.70 vs. 4.95 in females, with a sample 
of 6682 and 1330 males and females, respectively. Saxena (1984) performed his study on a non-Caucasian population, using a sample of males of Nigerian origin.

Ranking last of our simple regression variables is hand length (equations: $\mathrm{S} 5_{\mathrm{m}}$ and $\mathrm{S} 5_{\mathrm{f}}$ ). Of all the variables considered this is the one which would lead to the largest estimation error $(6 \mathrm{~cm}$ in males and $5.27 \mathrm{~cm}$ in females), although cross validation gives a lower pure error $(4.88 \mathrm{~cm}$ and $4.52 \mathrm{~cm})$. Hand length has also been applied in association with hand diameter by Saxena (1984), Bhatnagar et al. (1984) and AbdelMalek et al. (1990) on populations from Nigeria, India, and Egypt respectively. In the last of these studies, estimation error was $5.1 \mathrm{~cm}$

A variable for estimating stature which is widely referenced in the literature since it was first proposed by Chumlea, Roche, and Steinbaugh in 1985 is height of the knee. It was intended to represent the length of the distal segment of the lower extremities in persons who were bedridden or chair-bound. It is not a measurement of an osseous segment, as it includes two joints (ankle and knee) and the soft tissue of the heel and the thigh. In adult Caucasians the $R^{2}$ obtained was 0.65 in males, lower than that achieved by the 8 variables used in our work, and 0.66 in females, also lower than for our sample, except for foot length (0.59).

In Table 6 we compare heights estimated using some of the above-mentioned predictive equations with those estimated in our work, matching the results against the actual height of the sample. If we look at the equations presented in the previous table we can see that, with the exception of Han and Lean's equation of 1996 for females, all the others yield a statistically significant difference between estimated stature and stature measured directly and are therefore not applicable to our population. In the female sample, stature is underestimated in all cases, as it is in the male sample except when arm span is used, which gives a mean value higher than the actual measured value.

In the simple regression analysis, arm span is the isolated variable with the best correlation with stature, but we should bear in mind that it is a measurement that includes the length of the three segments of the upper extremity (upper arm, forearm, and hand). Meanwhile lower leg length, measuring the medial surface of the tibia, is the isolated bone segment that shows the best correlations with both stature and all the other extremity segments. This measurement will be the one of choice whenever it can be properly determined. Also, for bedridden subjects it presents fewer technical difficulties than the measurement of arm span.

\section{Estimation using multiple regression}

In males the first three equations of Table 4 best estimate stature; that is, they have the highest coefficient of determination $\left(R^{2}\right)$ and the lowest estimation error (RMSE and $P E)$. In the first equation, sitting height and length of thigh, lower leg, upper arm, and forearm $\left(\mathrm{M} 1_{\mathrm{m}}\right)$ are used as predictive variables; in the second, forearm length $\left(\mathrm{M} 2_{\mathrm{m}}\right)$ is excluded; and in the third, upper limb length is replaced by arm span $\left(\mathrm{M}_{\mathrm{m}}\right)$. In females, the first two equations are very similar in terms of accuracy. The first includes arm span, sitting height, and lengths of thigh and lower leg $\left(\mathrm{M}_{\mathrm{f}}\right)$, and the second includes sitting height and lengths of thigh, lower leg, foot, and upper arm. Therefore, when the impossibility of measuring stature is due to the fact that the person is unable to take up a standing position, we can estimate it using the following equations, with a confidence interval of $95 \%$, in the following manner:

—M1males : $R^{2}=0.978$

$$
\begin{aligned}
\text { Stature }= & {\left[1.346+1.023 * \mathrm{X}_{1}+0.957 * \mathrm{X}_{2}+0.530 * \mathrm{X}_{3}\right.} \\
& \left.+0.493 * \mathrm{X}_{4}+0.228 * \mathrm{X}_{5}\right] \pm 1.96 * 1.41 \mathrm{~cm}
\end{aligned}
$$

$\left(\mathrm{X}_{1}=\right.$ lower leg; $\mathrm{X}_{2}=$ sitting height; $\mathrm{X}_{3}=$ thigh; $\mathrm{X}_{4}=$ upper arm; $\mathrm{X}_{5}=$ forearm).

-M1 females: $R^{2}=0.959$

$$
\begin{aligned}
\text { Stature }= & {\left[1.772+0.159 * \mathrm{X}_{1}+0.957 * \mathrm{X}_{2}+0.424 * \mathrm{X}_{3}\right.} \\
& \left.+0.966 * \mathrm{X}_{4}\right] \pm 1.96 * 1.57 \mathrm{~cm}
\end{aligned}
$$

\begin{tabular}{|c|c|c|c|c|c|c|}
\hline \multirow{3}{*}{$\begin{array}{c}\text { Estimated Stature }(\mathrm{cm}) \\
\text { References }\end{array}$} & \multicolumn{6}{|c|}{ Variables } \\
\hline & \multicolumn{2}{|c|}{ Arm span } & \multicolumn{2}{|c|}{ Lower leg } & \multicolumn{2}{|c|}{ Foot } \\
\hline & males & females & males & females & males & females \\
\hline Steele and Chenier (1990) & & $164.7 \pm 7.3^{*}$ & & & & \\
\hline Giles and Vallandigham (1991) & & & & & $174.2 \pm 5.9^{*}$ & $162 \pm 4.7 *$ \\
\hline Han and Lean (1996) & $180.4 \pm 8^{*}$ & $166.6 \pm 6.2$ & & & & \\
\hline Brown, Whittemore, and Knapp (2000) & $181.2 \pm 7.9^{*}$ & $165.7 \pm 6.7^{*}$ & & & & \\
\hline Mohamty, Babu, and Nair (2001) & & $162.7 \pm 6.1^{*}$ & & & & \\
\hline Duyar, Pelín, and Zagyapan (2006) & & & $177 \pm 8.8 *$ & & & \\
\hline Present study & $179.4 \pm 8.9$ & $166.6 \pm 7$ & $179.5 \pm 8.8$ & $166.4 \pm 6.8$ & $179.4 \pm 8.1$ & $166.6 \pm 5.9$ \\
\hline
\end{tabular}

$\left(X_{1}=\right.$ arm span; $X_{2}=$ sitting height; $X_{3}=$ thigh; $X_{4}=$ lower leg $)$

When a pathology at the level of the spinal column

Table 6 Comparative study of simple regression equations

True stature: male: $179.5 \pm 9.6$; female: $166.6 \pm 7.7$

* Significant differences between estimated and true stature $(p<0.0001)$. 
means that a person cannot remain in a seated position properly, or when gluteal hypotrophy due to a person's degree of immobility advises against the measurement of sitting height, we can use equations $\mathrm{M} 12 \mathrm{v}$ and $\mathrm{M} 14 \mathrm{~m}$ for males and females respectively, which are based on upper and lower limb lengths:

-M12 males : $R^{2}=0.928$

$$
\begin{aligned}
\text { Stature }= & {\left[29.795+0.333 * X_{1}+0.935 * X_{2}+0.673 * X_{3}\right.} \\
& \left.+0.771 * X_{4}\right] \pm 1.96 * 2.57 \mathrm{~cm}
\end{aligned}
$$

$\left(\mathrm{X}_{1}=\right.$ arm span; $\mathrm{X}_{2}=$ lower leg; $\mathrm{X}_{3}=$ thigh; $\mathrm{X}_{4}=$ foot. $)$

-M14females: $R^{2}=0.875$

$$
\begin{aligned}
\text { Stature }= & {\left[35.709+0.328 * X_{1}+0.803 * X_{2}\right.} \\
& \left.+0.535 * X_{3}+0.973 * X_{4}\right] \pm 1.96 * 2.74 \mathrm{~cm}
\end{aligned}
$$

$\left(\mathrm{X}_{1}=\right.$ arm span; $\mathrm{X}_{2}=$ lower leg; $\mathrm{X}_{3}=$ thigh; $\mathrm{X}_{4}=$ foot. $)$

When the measurement of arm span or of any of the lengths included in the equations giving the best determination are ruled out for reasons of mobility, technical difficulty, amputation, or segment loss, we will choose the equation with the highest $R^{2}$ and the lowest estimation error that contains the variables that we can measure directly in a technically correct manner.

We can see that the greatest accuracy and precision in stature estimation is obtained from equations involving measurements of both the trunk and upper and lower limbs. When sitting height cannot be determined or may be altered, the best equations include lengths of upper limbs or arm span and the thigh, lower leg, and foot lengths. The equations that yield the poorest accuracy are those in which only upper limb length measurements are used.

When estimating the stature of persons with a disability that may affect the proportion of body segments, in addition to choosing the most appropriate equation, we must also take into account that the stature obtained is that which would correspond to that person if he or she had a harmonic development and it is not necessarily the same as their real height, i.e., their height if they could be measured properly in a standing position. This estimated measurement will, however, be of great use for any functional evaluations that we may wish to make.

\section{Conclusions}

Stature can be estimated with great accuracy and precision using predictive equations obtained in a contemporaneous sample of the same age, sex, and racial group.

The multiple regression equations which associate the lengths of trunk and both extremities yield the lowest error. In males the variables are: sitting height, lower leg length, thigh length, upper arm length, and forearm length. In females the variables are: sitting height, arm span, and lower leg and thigh lengths. However we can use equations with fewer variables, choosing those that include direct measurements that are able to be determined correctly and are not affected by any pathology or disability.

Future research will be required if the secular increase in height continues since there may be a change in bodily proportions.

\section{References}

Abdel-Malek AK, Ahmed AM, el-Sharkawi SA, el-Hamid NA (1990) Prediction of stature from hand measurements. Forensic Sci Int 46: 181-187

Bhatnagar DP, Thapar SP, Batish MK (1984) Identification of personal height from the somatometry of the hand in Punjabi males. Forensic Sci Int 24: 137-141

Brown JK, Whittemore KT, Knapp TR (2000) Is arm span an accurate measure of height in young and middle-age adults? Clin Nurs Res 9: 84-94

Chumlea WC, Roche AF, Steinbaugh ML (1985) Estimating stature from knee height for persons 60 to 90 years of age. J Am Geriatr Soc 33: 116-120

Chumlea WC, Guo SS, Steinbaugh ML (1994) Prediction of stature from knee height for black and white adults and children with application to mobility-impaired or handicapped persons. J Am Diet Assoc 94: 1385-1391

Chumlea WC, Guo SS, Wholihan K, Cockram D, Kuczmarski RJ, Johnson CL (1998) Stature prediction equations for elderly non-Hispanic white, non-Hispanic black, and Mexican-American persons developed from NHANES III data. J Am Diet Assoc 98: 137-142

Dupertuis CW, Hadden JA Jr (1951) On the reconstruction of stature from long bones. Am J Phys Anthropol 9: 15-53

Duyar I, Pelin C, Zagyapan (2006) A new method of stature estimation for forensic anthropological application. Anthropol Sci 114: 23-27

Engeland A, Bjorge T, Selmer RM, Tverdal A (2003) Height and body mass index in relation to total mortality. Epidemiology 14: 293-299

Eveleth PB, Tanner JM (1990) Worldwide variation in human growth. 2nd ed. Cambridge University Press, Cambridge, 176-207

Fogel RW (1994) Economic growth, population theory and physiology: The bearing of long-term processes on the making of economic policy. Am Economic Rev 84: 369-395

Forbes GB (1974) Stature and lean body mass. Am J Clin Nutr 27: 595-602

Frisancho A (1984) New standards of weight and body composition by frame size and height for assessment of nutritional status of adults and the elderly. Am J Clin Nutr 40: 808-819

Genovés S (1967) Proportionality of the long bones and their relation to stature among Mesoamericans. Am J Phys Anthropol 26: 67-77

Giles E, Vallandigham PH (1991) Height estimation from foot and shoeprint length. J Forensic Sci 36: 1134-1151 
Golshan M, Amra B, Hoghoghi MA (2003) Is arm span an accurate measure of height to predict pulmonary function parameters? Monaldi Arch Chest Dis 59: 189-192

Gordon CC, Buikstra JE (1992) Linear models for the prediction of stature from foot and boot dimensions. J Forensic Sci 37: 771-782

Guzmán C, Reinoza G, Hernández RA (2005) Estimación de la estatura a partir de la longitud de pierna medida con cinta métrica. Nutr Hosp 20: 358-363 [In Spanish]

Han TS, Lean ME (1996) Lower leg length as an index of stature in adults. Int J Obes Relat Metab Disord 20: 21-27

Harris JA, Benedict FG (1918) A Biometric Study of Human Basal Metabolism. Proc Natl Acad Sci USA 4: 370-373

Hernández M, Castellet J, Narvaiza JL, Rincón JM, Ruiz I, Sánchez E, Sobradillo B, Zurimendi A (1988) Curvas y Tablas de Crecimiento. Ed. Garsi. Madrid [In Spanish]

Hibbert ME, Lanigan A, Raven J, Phelan PD (1988) Relation of armspan to height and the prediction of lung function. Thorax 43: 657-659

Iwanaga K (2005) The Biological Aspects of Physiological Anthropology with Reference to its Five Keywords. J Physiol Anthropol Appl Human Sci 24: 231-235

Jarzem PF, Gledhill RB (1993) Predicting height from arm measurements. J Pediatr Orthop 13: 761-765

Knudson RJ, Slatin RC, Lebowitz MD, Burrows B (1976) The maximal expiratory flow-volume curve. Normal standards, variability, and effects of age. Am Rev Respir Dis 113: 587600

Kouda K (2005) Interrelationships among Whole-Body Coordination, Functional Potentiality, and Environmental Adaptability. J Physiol Anthropol Appl Human Sci 24: 241242

Nath S, Badkur P (2002) Reconstruction of Stature from Long Bone Length. In Bhasin MK, Malik SL eds. Anthropology: Trends and Applications. Kamla-Raj, 109-114

Nunes de Mendoça MC (1998) Contribución para la identificación humana a partir del estudio de las estructuras óseas. Determinación de la talla a través de la longitud de los huesos largos. UCM, Madrid [PhD thesis] [In Spanish]

Ohyama S, Hisinaga A, Inamasu T, Yamamoto A, Hirata M, Ishinishi N (1987) Some Secular Changes in Body Height and Proportion of Japanese medical Students. Am J Phys Anthropol 73: 179-183

Ozaslan A, Iscan MY, Ozaslan I, Tugcu H, Koc S (2003) Estimation of stature from body parts. Forensic Sci Int 132: 40-45
Saxena SK (1984) A study of correlations and estimation of stature from hand length, hand breadth and sole length. Anthropol Anz 42: 271-276

Singh TS, Phookan MN (1993) Stature and footsize in four Thai communities of Assam, India Anthropol Anz 51: 349 355

Steele MF, Chenier TC (1990) Arm-span, height, and age in black and white women. Ann Hum Biol 17: 533-541

Tanner JM, Hayashi T, Preece MA, Cameron N (1982) Increase in length of leg relative to trunk in Japanese children and adults from 1957 to 1977: comparison with British and with Japanese Americans. Ann Hum Biol 9: 411-423

Telkka A (1950) On the prediction of human stature from the long bones. Acta Anat 9: 103-117

Trotter M (2004) Operations at Central Identification Laboratory. 1949. In Bernard Becker Medical Library Digital Collection. Washington University School of Medicine, St. Louis, Missouri

Trotter M, Gleser GC (1958) A re-evaluation of estimation of stature based on measurements of stature taken during life and of long bones after death. Am J Phys Anthropol 16: 79123

Trotter M, Gleser GC (1977) Corrigenda to "estimation of stature from long limb bones of American Whites and Negroes," American Journal Physical Anthropology (1952). Am J Phys Anthropol 47: 355-356

Villanueva E, Castilla J (1998) Identificación del cadáver. In Gisbert Calabuig JA ed. Medicina Legal y Toxicología. Masson SA, Barcelona, 1011-1020 [In Spanish]

Yousafzai AK, Filteau SM, Wirz SL, Cole TJ (2003) Comparison of armspan, arm length and tibia length as predictors of actual height of disabled and nondisabled children in Dharavi, Mumbai, India. Eur J Clin Nutr 57: 1230-1234

Zorab PA, Prime FJ, Harrison A (1963) Estimation of height from tibial length. Lancet 26: 195-196

Received: June 3, 2008

Accepted: January 16, 2009

Correspondence to: Alicia Canda, Centro de Medicina del Deporte, Consejo Superior de Deportes, c/Martín Fierro s/n, 28040 Madrid, Spain

Phone: +34-91-589-6894

Fax: +34-91-589-0517

e-mail: alicia.canda@csd.mec.es 